\title{
Two decades of percutaneous transjejunal biliary intervention for benign biliary disease: a review of the intervention nature and complications
}

\author{
Duveken B. Y. Fontein • Robert N. Gibson • Neil A. Collier • Gabrielle T. W. Tse • \\ Luke L. K. Wang • Tony G. Speer • Richard Dowling • Amanda Robertson • \\ Benjamin Thomson • Albert de Roos
}

Received: 30 April 2011 /Revised: 29 June 2011 / Accepted: 11 July 2011 / Published online: 28 July 2011

(C) The Author(s) 2011. This article is published with open access at Springerlink.com

\begin{abstract}
Objective To assess outcomes of percutaneous transjejunal biliary intervention (PTJBI) in terms of success and effectiveness in patients with a Roux-en-Y hepaticojejunostomy for benign biliary strictures and stones.

Methods Clinical and radiographic records of 63 patients with a Roux-en-Y choledochojejunostomy or hepaticojejunostomy for benign disease who underwent at least one PTJBI between 1986 and 2007 were reviewed. Effectiveness was determined by successful access rate, rates of
\end{abstract}

\section{B. Y. Fontein $(\triangle)$}

Department of Surgery, Leiden University Medical Center, P.O. Box 9600, 2300, RC Leiden, The Netherlands

e-mail: d.b.y.fontein@lumc.nl

R. N. Gibson - G. T. W. Tse • L. L. K. Wang • R. Dowling Department of Radiology, University of Melbourne,

The Royal Melbourne Hospital,

Grattan Street,

Parkville 3050, Victoria, Australia

R. N. Gibson

e-mail: r.gibson@unimelb.edu.au

N. A. Collier · A. Robertson $\cdot$ B. Thomson

Department of Surgery, University of Melbourne,

The Royal Melbourne Hospital,

Grattan Street,

Parkville 3050, Victoria, Australia

T. G. Speer

Department of Gastroenterology, University of Melbourne,

The Royal Melbourne Hospital,

Grattan Street,

Parkville 3050, Victoria, Australia

A. de Roos

Department of Radiology, Leiden University Medical Center, P.O. Box 9600, 2300, RC Leiden, The Netherlands stricture dilatation and/or stone extraction, morbidity, complications and hospitalisation.

Results PTJBI was attempted 494 times. Successful access to the Roux-en-Y was accomplished in $93 \%$ of interventions. After access to the Roux-en-Y was granted, all strictures were effectively dilated. Ninety-seven percent of extraction attempts of intrahepatic calculi were successful. The median number of interventions per patient was five. The median interval between interventions was 51.5 weeks (range 2.7-1,279.6 weeks). The early complication rate was $3 \%$. Morbidity, measured in terms of cholangitis episodes was $14 \%$, in 25 out of 63 patients. Mean hospitalisation was 4.1 nights per year.

Conclusion PTJBI is safe and effective in treating benign biliary strictures and/or calculi. High success rates and short hospitalisation periods, together with few complications make it a well-accepted and integral part of managing complex biliary problems.

Keywords Roux-en-Y hepatojejunostomy · Dilatation . Stricture $\cdot$ Calculi $\cdot$ Cholangiography

\section{Introduction}

Benign biliary strictures and intrahepatic calculi present challenges for long-term management $[1,2]$. While most patients are well-managed by either a single surgical or endoscopic intervention, management by a single approach may be difficult in patients experiencing recurrent biliary strictures and/or intrahepatic stones. Recurrent stricturing following surgical repair has been reported to range between 5 and 45\% [3, 4]. Endoscopic intervention is frequently not possible following a Roux-en-Y hepaticoje- 
junostomy or choledochojejunostomy [5]. Currently, conventional transhepatic radiological techniques for stricture dilatation or stone removal as an adjunct to surgery are commonly applied in most hospitals throughout the world. However, percutaneous transjejunal biliary intervention (PTJBI), a relatively unfamiliar technique, has shown promising results, although it has yet to be integrated into daily practice $[6,7]$. Our institution, a hepatobiliary referral centre, has substantially replaced conventional techniques with PTJBI for non-transplant benign biliary strictures and intrahepatic stones. Although many researchers are aware of this technique, there are only a few large studies reported to date and even fewer studies report single-institution experiences with long follow-up periods. The transjejunal approach uses an efferent or afferent limb of the Roux-en-Y loop, which is fixed to the peritoneum with the fixation site marked with surgical clips. Radiological access is provided to the biliary tree for diagnostic cholangiography, stricture dilatation and intrahepatic stone clearance [7-12]. A number of reports describe good initial results with PTJBI [7, 9-14]; however, they lack long-term follow-ups. The present study is a descriptive retrospective longitudinal study and reviews more than two decades of experience with PTJBI at a single institution, allowing for a more complete assessment of the role of PTJBI in the management of complex biliary problems.

\section{Materials and methods}

Study population

Seventy-nine patients with Roux-en-Y hepaticojejunostomies or choledochojejunostomies resulting from bile duct injuries or benign biliary diseases were assessed for this investigation. Data were gathered from case notes and radiological records. Institutional ethics review board permission was obtained and individual patient consent was not required.

Patients were examined by one radiologist (22 years of experience). Diagnostic categories included post-operative bile duct injuries (11 men, 28 women), primary sclerosing cholangitis (PSC) (three men, three women), recurrent pyogenic cholangitis (two men, four women), Caroli's disease (three men, four women) and other stricture or stone aetiologies, namely hydatid disease (two men), autoimmune sclerosing cholangitis (one man) and intrahepatic stone disease (one man, one woman). Patients were divided into two groups according to their dominant prognosis. Patients with post-cholecystectomy injuries, primary sclerosing cholangitis and other benign stricture diseases [hydatid disease (two) and autoimmune sclerosing cholangitis (one)] were categorised as the 'Stricture group' (48 patients) and patients with recurrent pyogenic chol- angitis, Caroli's disease and other intrahepatic stone disease were labelled the 'Stone group' (15 patients). A further classification based on a modification of the Bismuth classification was applied to patients with postcholecystectomy strictures [15]. There was only one patient with Bismuth type I injury, so Bismuth types I and II were grouped together in this analysis. Eighteen patients with Bismuth type I and II injuries were present, eight type III, 13 type IV and there were no patients with type V injuries.

The follow-up period was defined as the time (weeks) between the first attempt to access the jejunal loop and the last procedure, clinical review or death. The number, type and frequency of biliary interventions per patient were recorded.

\section{Radiological technique}

Between January 1986 and December 2007, 63 patients required percutaneous access to the biliary tree. Sixteen patients did not require percutaneous access and were excluded; 15 patients remained asymptomatic with normal liver-function test results and one patient could not be located in the follow-up. The Roux loop was surgically fixed to the abdominal wall in 57 patients $(90.5 \%)$, and six patients had unfixed Roux loops constructed at other centres (Table 1).

PTJBI was performed via the fixed limb (either afferent or efferent limb) of a Roux-en-Y hepaticojejunostomy which had been created to repair biliary strictures or bile duct injuries, or specifically for PTJBI access to treat strictures or stones.

Table 1 Baseline characteristics

\begin{tabular}{lll}
\hline Patient characteristics & $n$ & $\%$ \\
\hline Gender & 25 & 39.7 \\
Men & 38 & 60.3 \\
Women & & \\
Age (years) & 62 & \\
Mean & $32-97$ & \\
Range & & 90.5 \\
Roux-loop characteristics & 57 & 9.5 \\
Fixed loop & 6 & \\
Unfixed loop & & 62 \\
Stricture group & 39 & 9.5 \\
Post-cholecystectomy injury & 6 & 5 \\
Primary sclerosing cholangitis & 3 & \\
Other & & 9.5 \\
Stone group & 6 & 11 \\
Recurrent pyogenic cholangitis & 7 & 3 \\
Caroli's disease & 2 & \\
Other & &
\end{tabular}


The efferent limb of the Roux loop was surgically fixed to the parietal peritoneum in a right anterior location, or the afferent limb was fixed anteriorly in the central upper abdomen [7]. Marking surgical clips, sometimes in combination with prior $\mathrm{CT}$ images and/or transjejunal cholangiograms provided information about the fixation site for loop puncture. Unfixed loops were accessed percutaneously with knowledge of previous CT, CT intravenous cholangiography (CT-IVC) or by 'roadmapping' with percutaneous transhepatic cholangiography (PTC) to opacify the Roux loop. Not all patients had marking clips, as some were transferred from other institutions or had surgery before the introduction of this technique.

One radiologist (22 years of experience) performed most interventions and the rest were performed by other interventional radiologists on site. Most patients were treated in the afternoon and observed overnight in hospital. Before intervention, intravenous broad-spectrum antibiotics were administered. Four hundred and eighty-eight procedures were performed under conscious sedation (intravenous fentanyl and midazolam), with three patients receiving a general anaesthetic in accordance with the patients' wishes (one to three times).

The Roux loop was punctured under fluoroscopic guidance with a 22-gauge Chiba needle (Cook, Brisbane, Australia); small volumes of contrast materials were injected, with the needle position adjusted until opacification of the jejunal lumen was achieved. No anchoring device was required as peritoneal fibrosis provided sufficient anchoring. In some patients, an operatively placed tube was left in position at the time of biliary-enteric anastomosis and Roux-loop creation. This provided Rouxloop access for the first PTJBI 6-8 weeks post-operatively. A 0.035-inch Amplatz guide-wire (Cook, Brisbane, Australia) was inserted into the lumen aided by a Neff, or occasionally a Cope, introduction set (Cook, Brisbane, Australia). A biliary manipulation catheter (Cook, Brisbane, Australia) with a very short distal bend and high torque was then used with the guidewire to negotiate the bowel lumen. Upon reaching the anastomosis an Amplatz wire, or sometimes, a Newton guidewire (Cook, Bloomington, IN, USA) or hydrophilic guidewire (Terumo, Tokyo, Japan) was used to cross the anastomosis, the direction being controlled by the catheter (Fig. 1) [7]. The tendency of longer Roux loops to telescope, which occurred in some patients, was overcome by manipulating the loop so that it coiled on the catheter. Occasionally, this was maintained by use of an 8- or 10-Fr sheath, particularly when dealing with stone extractions.

Stricture dilatation was performed in one to three dilatations, depending on stricture resistance. We used angioplasty balloon catheters (Cook, Brisbane, Australia) with a diameter of 4-10 mm (Fig. 1). The adjacent normal duct diameter determined the diameter of the balloon. Inflation pressures ranged from 6 to $15 \mathrm{~atm}$ [7]. Successful dilatation was defined as inflation of the balloon across the stricture achieving balloon inflation and residual lumen of at least $50 \%$ of the adjacent duct diameter. Calculi were extracted intact or fragmented, and extracted or flushed into the jejunal loop with a helical wire biliary stone basket and/ or balloon catheter (Cook, Brisbane, Australia) (Fig. 2) [7]. Ancillary stone destruction methods were not required.

Follow-up was by clinical review. Most patients underwent elective dilatations at regular intervals ranging from 3 to 12 months in the absence of clinical symptoms and/or cholangitis. The intervals between elective dilatations were based on clinical and radiological observations based on the severity of stricturing, cholangiographic response to dilatation at intervention and symptom-free intervals. In patients with calculi, the interval time was based on the completeness of stone clearance at previous intervention and the presence of clinical cholangitis. Non-elective PTJBI was performed if patients developed clinical cholangitis or jaundice. An important measure of morbidity was interval cholangitis between interventions. CT or CT-IVC was used to exclude abscesses in the presence of sepsis and to identify isolated obstructed segments [7].

\section{Statistical analysis}

Stata8 (StataCorp, College Station, TX, USA, 1984-2003) was used for statistical analysis of the data. Categorical data for different analysis groups were compared using the Chisquared test or Fisher's exact test. Poisson regression determined the numbers of interventions in the different analysis groups. We tested for proportions to determine frequencies of characteristics among different groups of patients. The Kruskal-Wallis test was applied to test for differences between the various proportions.

\section{Results}

A total of 494 interventions were performed. At least one percutaneous access to the Roux loop was attempted at each intervention. The Roux loop was initially successfully accessed on 425 occasions ( $86 \%$ ). This value increased to 459 (93\%) after opacification of the Roux loop by PTC roadmapping. Nine procedures were abandoned as percutaneous transjejunal access was still unsuccessful after PTC roadmapping, and nine other procedures were discontinued as no stones or strictures appeared at PTC roadmapping and no further intervention was required. Percutaneous transhepatic intervention was performed on 13 occasions, after failure of PTJBI, with biliary catheters left in place for drainage in 11 patients (2\%) (eight Stricture group patients 


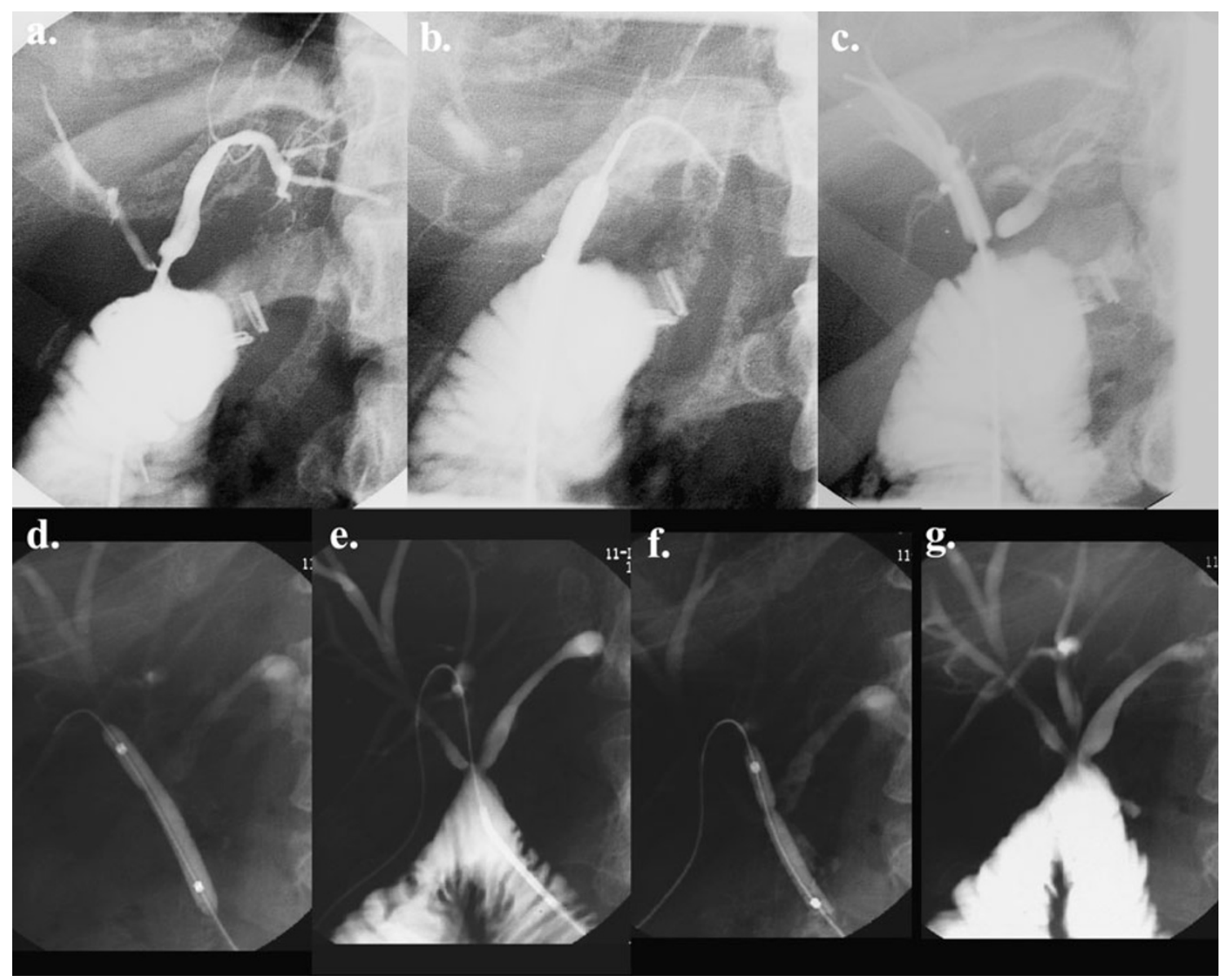

Fig. 1 Balloon dilatation. Transjejunal cholangiogram showing postcholecystectomy bile duct injury (Bismuth III) treated by percutaneous transjejunal biliary dilatation with three strictures dilated from a single transjejunal approach. a Pre-angioplasty. b Angioplasty of the left hepatic duct anastomotic stricture. c, d Angioplasty of the right

and three Stone group patients). Four biliary interventions were through an already existing transhepatic drainage catheter. In some cases, failure to access the Roux loop was because of the patient's obesity, or unclear clip marking, or in patients with unmarked Roux loops. As the contrast material is injected to identify the needle position within the loop, after a number of unsuccessful passes, the field of view may become obscured and targeting is more difficult. After nine interventions, a removable plastic stent (Cook, Brisbane, Australia) was placed in the Roux loop (in six patients). A permanent metal Wallstent (Boston Scientific, Galway, Ireland) was placed via the Roux loop in one instance in a patient with Caroli's disease with secondary duct stricturing, and on three occasions in a patient with end-stage PSC.

Access to a fixed Roux loop was attempted 455 times and was successful on 426 occasions (94\%) compared with 33 out of 39 attempts $(85 \%)$ in patients with an unfixed Roux loop $(p=0.031)$. If an efferent or afferent loop was not marked with clips, patients underwent CT or CT-IVCs, choosing the shortest loop which had an anterior location anterior hepatic duct anastomotic stricture. e, f Angioplasty of the right posterior hepatic duct anastomotic stricture. g Post-angioplasty cholangiogram - bile ducts and anastomoses are incompletely distended and hence have the appearance of residual stricturing

with safe percutaneous access on the basis of the CT. All strictures present were dilated successfully and out of 169 interventions for the extraction of one or more calculi in all patients, 157 attempts (93\%) were successful (3\% failed extraction, $2 \%$ not extracted and $2 \%$ not specified).

The mean time from biliary-enteric anastomosis to the first radiological intervention was 2.9 years [standard deviation (SD) 5.4 years]. Patients in the Stricture group had longer intervals between biliary-enteric anastomosis and initial intervention than patients in the Stone group [mean 1.52 years (SD 6.03 years) versus 3.47 years (SD 2.66 years) respectively, $p=0.031$ ].

The number of interventions and the interval between interventions varied considerably between patients, ranging from 1 to 40 interventions over the follow-up period (mean 7.8 interventions, median 5 interventions, SD 8.3 interventions). The mean interval between interventions was 51.5 weeks (median 30.9 weeks, SD 62.9 weeks) (Table 2). Patients in the Stone group required fewer interventions on a yearly basis than patients in the Stricture group $(p=0.045)$. 
Fig. 2 Calculi extraction. Transjejunal cholangiogram showing: a post-

cholecystectomy anastomotic stricture with numerous multisegment intrahepatic stones; b-d PTJBI following stricture balloon dilatation and stone clearance using a combination of flushing and basket extraction. a, (b The right hepatic duct; c, d the left hepatic duct and left segmental duct
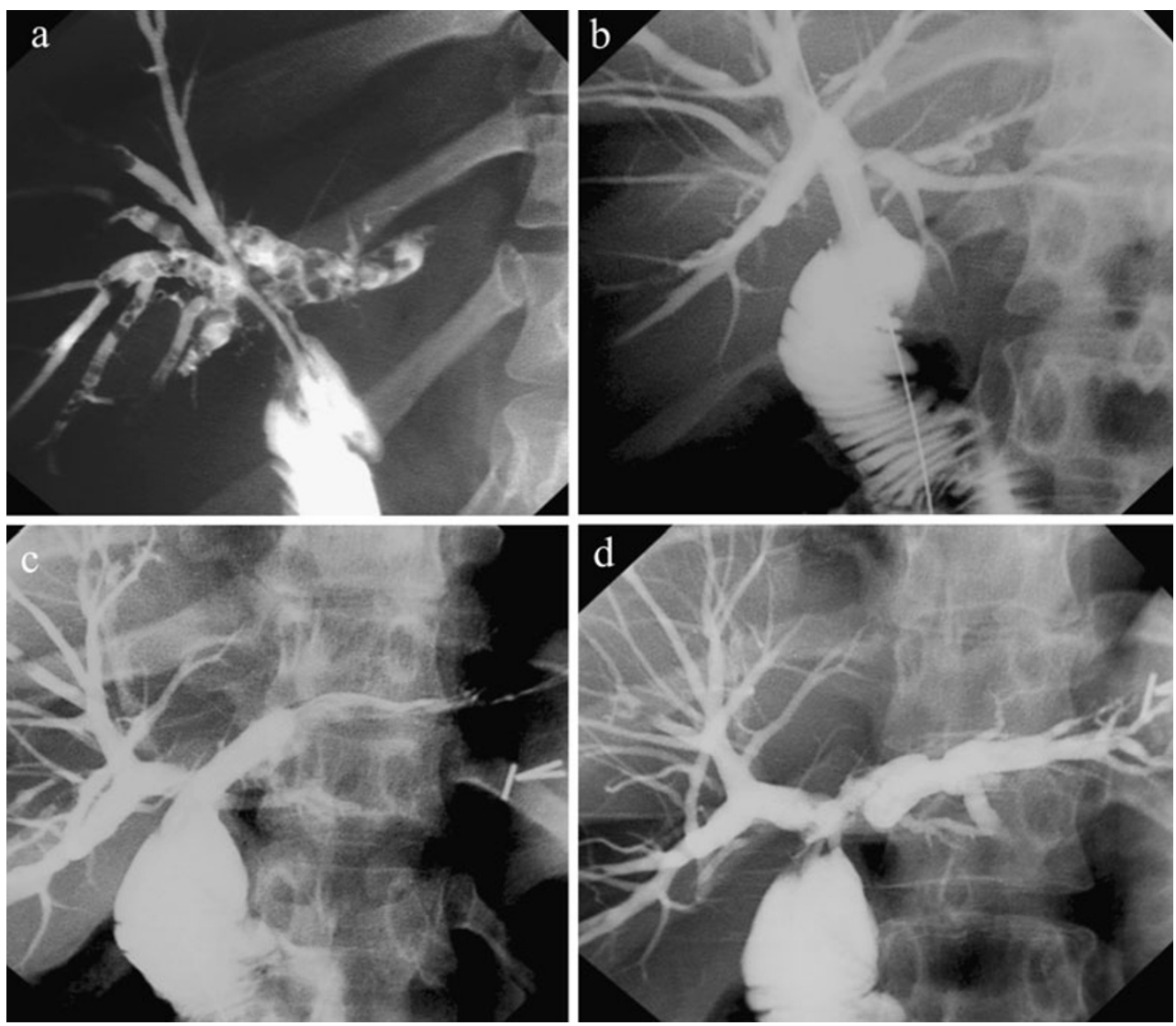

For elective interventions the standard duration in hospital was one night (Fig. 3). Nine admissions included multiple interventions, such as balloon dilatation or stone extraction over several days. Longer hospitalisation periods were usually in association with Roux loop repair/refixation or hepatectomy to treat intrahepatic stones that proved difficult to treat with PTJBI. The mean hospitalisation period, calculated in nights per patient per year, was 4.1 (median 2.5 nights, SD 4.6 nights) and was similar between the different patient subgroups. The mean followup was 7.54 years (median 5.4 years, SD 7.47 years).

The liver-function test data were incomplete and obtained retrospectively from only 50 patients. Twenty patients had at least one test result that was abnormal. Seven patients $(37 \%)$ had at least two abnormal test results. As the liver-function tests were incomplete, we did not attempt to correlate abnormal liver function and rates of (re-)stricturing and the presence of calculi as a long-term analysis.

\section{Morbidity}

Interval cholangitis occurred on 67 occasions (14\%). Of all cholangitis episodes, $41(62 \%)$ were associated with recurrence of strictures, nine $(13 \%)$ with recurrent stones and ten $(14 \%)$ with concurrent recurrence of strictures and stones. In seven episodes of interval cholangitis (11\%), neither strictures nor stones were identified at transjejunal cholangiography. There was no correlation between the different subgroups and interval cholangitis (Table 3 ).

\section{Complications}

Fourteen procedure-related complications occurred: erythematous reaction (one), post-procedure sepsis (eight), wound abscess (one), perforation of the Roux loops (three) and left portal vein punctures followed by haemorrhages and ascites (one).

The non-procedure-related complications of secondary biliary cirrhosis (two) and oesophageal varices, are inferred to be due to secondary biliary cirrhosis (two). One patient with PSC developed cholangiocarcinoma and one patient with post-cholecystectomy injury developed hepatocellular carcinoma. Six patients died between 4.4 months and 6.1 years after the last intervention; causes of death were hepatic failure (two patients, 5.7 months and 3.8 years after last intervention), cardiac failure (one patient, 8.5 months after last intervention), aspiration pneumonia (1 patient, 6.1 years after last intervention) and unknown reasons (two patients, 4.4 months and 4.7 years after last intervention).

Surgical intervention was required for several reasons: one patient required fixation of an initially unfixed Roux 


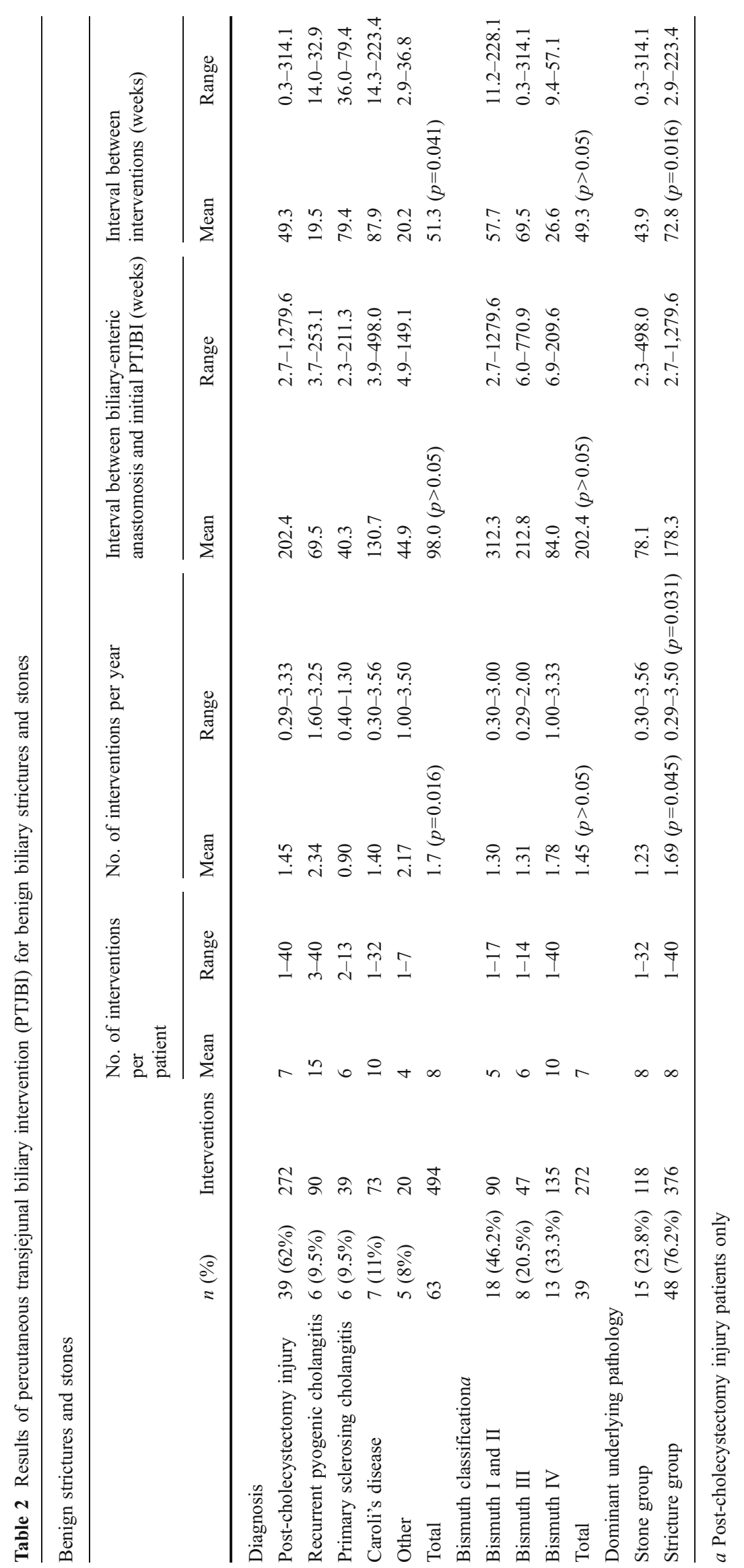




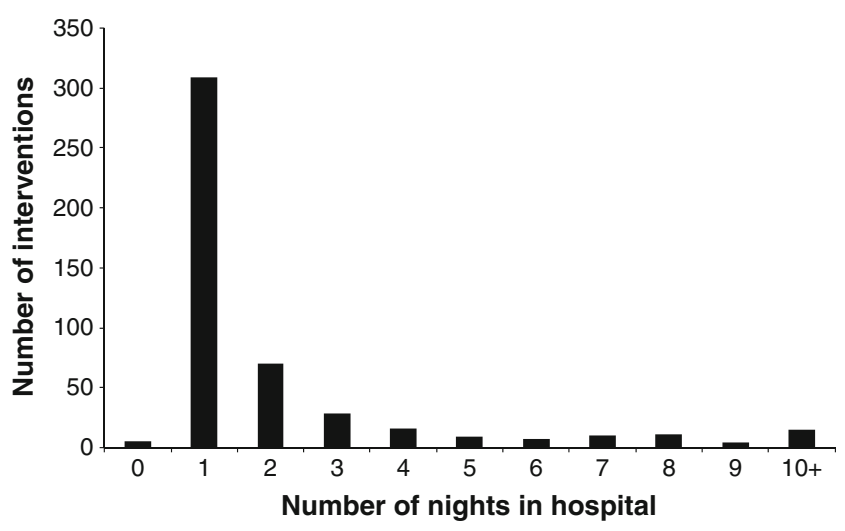

Fig. 3 Number of nights in hospital per intervention in all patients. Histogram depicting length of hospital stay for biliary intervention

loop to facilitate percutaneous access to the biliary tree, six patients with an initially fixed loop required re-fixation for more favourable access, and two patients required a second biliary-enteric anastomosis to the intrahepatic biliary tree (both were segment five hepaticojejunostomies created to access and treat intrahepatic segment five stone disease). An additional three patients had partial liver resections to treat intrahepatic stone disease.

\section{Discussion}

Benign biliary strictures and intrahepatic stone diseases represent a complex group of patients that present challenges for successful long-term health management. Currently, while the preferred treatment for post-operative biliary strictures remains surgical repair, repeat surgery is not always possible for recurrent strictures and stones [2]. Endoscopic retrograde cholangiography and stricture dilatation is usually limited to common duct strictures and is dependent on adequate duodenal access [16]. Although initial results were promising, long-term technical success rates are still relatively lacking and have been reported to be as low as $10 \%$ [17]. Percutaneous transhepatic biliary intervention is limited by its inability to access all segments of the biliary tree in a single puncture and carries significant morbidity as well as patient discomfort [18, 19]. The importance of maintaining access to the biliary tree in patients with complex benign biliary strictures and stones is evident as stricture recurrence requiring radiological or surgical re-intervention ranges from 10 to $45 \%[3,11,20$ 23]. In fact, results may underestimate the true recurrence rate as many studies have short follow-up times and recurrence is unpredictable, sometimes occurring many years after repair [2, 24-27]. The present series demonstrates several advantages of PTJBI in terms of successful access, stone and stricture clearance, frequency of interventions, short hospitalisation and few complications in relation to conventional methods of treatment.

In our experience, regular elective intervention at an early stage provides better clinical and cholangiographic long-term results rather than performing intervention only when clinical symptoms develop. The standard practice at our institution is to undertake more frequent interventions in the early stage (approximately every 3 months), after which the interval is lengthened according to the clinical status and cholangiographic appearances (usually 6-month intervals), until the patient is clinically and cholangiographically stable over several elective procedures. Our study is limited in the inability to compare our results of elective interventions with percutaneous transhepatic or endoscopic interventions. The most appropriate interval between interventions is difficult to evaluate based on the data analysis (and is absent from the literature); in our clinical practice the interval is based on the severity of stricturing at initial dilatation and clinical and cholangiographic results following intervention.

High success rates for stone clearance and stricture dilatation were established in the present series and compare favourably with transhepatic intervention, reporting successful dilatation rates from 67 to $90 \%$ [4]. Our immediate procedure-related complication rate of $3 \%$ (minor and major) differs from rates for similar complica-

Table 3 Number of episodes of interval cholangitis per patient grouped by diagnosis

Episodes of interval cholangitis

\begin{tabular}{|c|c|c|c|c|c|}
\hline Diagnosis & No. of patients & $\begin{array}{l}\text { Total no. of } \\
\text { interventions }\end{array}$ & Total no. of episodes (\%) & $\begin{array}{l}\text { Mean episodes } \\
\text { per patient }\end{array}$ & Median (range) \\
\hline Post-cholecystectomy injury & 39 & 272 & $42(15 \%)$ & 1.1 & $0(0-7)$ \\
\hline Primary sclerosing cholangitis & 6 & 90 & $10(11 \%)$ & 1.7 & $1.5(0-5)$ \\
\hline Recurrent pyogenic cholangitis & 6 & 39 & $2(5 \%)$ & 0.3 & $0(0-1)$ \\
\hline Caroli's disease & 7 & 73 & $11(15 \%)$ & 1.6 & $1(0-5)$ \\
\hline Other & 5 & 20 & $2(10 \%)$ & 0.4 & $0(0-2)$ \\
\hline Total & 63 & 494 & $67(14 \%)$ & $1.1(\mathrm{p}>0.05)$ & \\
\hline
\end{tabular}


tions in transhepatic intervention (14.5-23.5\%) and endoscopic treatment $(9-40 \%)$ [28-31]. Three patients had perforation of the Roux loop; this resulted from overvigorous dilatation of the percutaneous track in our early experience using co-axial dilators to allow insertion of a working sheath of $14-16 \mathrm{Fr}$. Patients underwent surgical repair of the perforated Roux loop; there were no deaths or major surgical complications following surgical repair. Subsequent to this event, however, sheath diameters were limited to $10-12 \mathrm{Fr}$.

There is some variation in the frequency of interventions within the different groups. Patients in the Stone group had longer intervals between interventions than other patients $(p=0.016)$, which was also exemplified in the number of interventions on a yearly basis $(p=0.045)$. Additionally, patients with PSC underwent more frequent dilatations than the post-cholecystectomy injury group on the basis that the disease is more likely to be progressive, as well as our clinical impression that this resulted in better health in the intervals. Of the post-cholecystectomy patients, Bismuth types III and IV injuries had greater need for accessing the Roux loop for subsequent interventions. This is consistent with findings by Al-Ghnaniem and Benjamin [8], and also parallels the common experience of poorer surgical outcomes with higher Bismuth grade strictures or injuries [32].

Currently no definitive treatment to combat the recurrence of strictures and calculi exists. Whilst there are no hard data to establish that preventive intervention in asymptomatic patients is beneficial, the authors firmly believe that this is the case for benign strictures with high risk of recurrence. This is based on the tendency of stricture dilatation to become progressively more stable after a number of dilatations, particularly with the tighter strictures. Furthermore, some patients became symptomatic with cholangitis in the month before the planned dilatation when an attempt was made to increase the interval between dilatations. A disadvantage of our approach is the need for regular interventions at 3- to 12-month intervals depending on the observed recurrence rates and the patient's clinical condition. Nevertheless, in our opinion the percutaneous transjejunal approach is now the best available minimally invasive intervention available in terms of safety, effectiveness, patient acceptance and length of hospital stay.

The reported rate of cholangitis in patients with postcholecystectomy biliary strictures ranges between 20 and $32 \%[33,34]$. However, it is not always a reliable indicator of recurrent biliary obstruction $[35,36]$. Our study supports this view as most of the recurrent strictures were not associated with cholangitis; $14 \%$ of interventions were preceded by cholangitis. Similarly, the absence of clinical cholangitis does not indicate the absence of restenosis; most episodes of strictures and calculi, respectively 86 and $89 \%$, were not preceded by cholangitis.
Clinical follow-up in terms of regular liver-function tests was incomplete in some patients. Of the 50 patients who underwent liver-function tests, only seven patients had two or more abnormal test results. Additionally, liver cirrhosis was usually a clinical diagnosis. Liver biopsy to objectivise biliary fibrosis or cirrhosis was not routine at our institution, regardless of treatment mode, which prevents accurate determination of the rate of longer term cirrhosis. This information, whilst clearly desirable, is however relatively deficient for long-term outcomes in this complex group of patients.

Percutaneous transhepatic stricture dilatation is still utilised for treatment of recurrent strictures with or without intrahepatic stones. This approach, however, associated with significant morbidity and discomfort, has a reported stricture recurrence rate of up to $34 \%$ of patients at 3 years, and requires long-term indwelling percutaneous catheters for acceptable results $[9,13,37,38]$. In the present investigation, catheters were only left in place in the case of short-term planned repeat interventions (usually in the same admission) for stone disease, or in the case of purulent cholangitis, to ensure good immediate drainage. The transjejunal approach eradicates this need for long-term transhepatic catheters, and multiple segments of the biliary tree can be accessed through a single access route.

To be effective and acceptable as a procedure, PTJBI should provide the ability to repeatedly access the biliary tree over a long period for treatment of strictures and intrahepatic stones. The procedure must have low morbidity rates, reasonably short periods of hospitalisation, a good quality of health between interventions and a high level of patient acceptance. Our experience suggests that PTJBI performs well in all of these areas and is an invaluable part of the management of benign biliary strictures and intrahepatic stone disease.

Open Access This article is distributed under the terms of the Creative Commons Attribution Noncommercial License which permits any noncommercial use, distribution, and reproduction in any medium, provided the original author(s) and source are credited.

\section{References}

1. Blumgart LH, Kelley CJ, Benjamin IS (1984) Benign bile duct stricture following cholecystectomy: critical factors in management. Br J Surg 71:836-843

2. Lillemoe KD, Pitt HA, Cameron JL (1992) Current management of benign bile duct strictures. Adv Surg 25:119-174

3. Hall JG, Pappas TN (2004) Current management of biliary strictures. J Gastrointest Surg 8:1098-1110

4. Laasch HU, Martin DF (2002) Management of benign biliary strictures. Cardiovasc Intervent Radiol 25:457-466 
5. Saleem A, Baron TH, Gostout CJ, Topazian MD, Levy MJ, Petersen BT, Wong Kee Song LM (2010) Endoscopic retrograde cholangiopancreatography using a single-balloon enteroscope in patients with altered Roux-en-Y anatomy. Endoscopy 42:656-660

6. Hutson DG, Russell E, Levi JU, Jeffers LJ, Reddy KR, Yrizarry JM, Scagnelli T, Sleeman D, Schiff ER, Livingstone AS (2001) Dilatation of biliary strictures through the afferent limb of a Rouxen-Y choledochojejunostomy in patients with sclerosing cholangitis. World J Surg 25:1251-1253

7. McPherson SJ, Gibson RN, Collier NA, Speer TG, Sherson ND (1998) Percutaneous transjejunal biliary intervention: 10-year experience with access via Roux-en-Y loops. Radiology 206:665-672

8. Al-Ghnaniem R, Benjamin IS (2002) Long-term outcome of hepaticojejunostomy with routine access loop formation following iatrogenic bile duct injury. Br J Surg 89:1118-1124

9. Hutson DG, Russell E, Yrizarry J et al (1998) Percutaneous dilatation of biliary strictures through the afferent limb of a modified Roux-en-Y choledochojejunostomy or hepaticojejunostomy. Am J Surg 175:108-113

10. Maroney TP, Ring EJ (1987) Percutaneous transjejunal catheterization of Roux-en-Y biliary-jejunal anastomoses. Radiology 164:151-153

11. Perry LJ, Stokes KR, Lewis WD, Jenkins RL, Clouse ME (1995) Biliary intervention by means of percutaneous puncture of the antecolic jejunal loop. Radiology 195:163-167

12. Russell E, Yrizarry JM, Huber JS, Nunez D Jr, Hutson DG, Schiff E, Reddy KR, Jeffers LJ, Williams A (1986) Percutaneous transjejunal biliary dilatation: alternate management for benign strictures. Radiology 159:209-214

13. Castaing D, Azoulay D, Bismuth H (1999) Percutaneous catheterization of the intestinal loop of hepatico-jejunostomy: a new possibility in the treatment of complex biliary diseases. Gastroenterol Clin Biol 23:882-886

14. Schweizer WP, Matthews JB, Baer HU, Nudelmann LI, Triller J, Halter F, Gertsch P, Blumgart LH (1991) Combined surgical and interventional radiological approach for complex benign biliary tract obstruction. Br J Surg 78:559-563

15. Jarnagin WR, Blumgart LH (2000) Benign biliary strictures. In: Blumgart LH, Fong Y (eds) Surgery of the liver and biliary tract. Harcourt, London, pp 895-933

16. Ramos-De la Medina A, Misra S, Leroy AJ, Sarr MG (2008) Management of benign biliary strictures by percutaneous interventional radiologic techniques (PIRT). HPB (Oxford) $10: 428-432$

17. Adler DG, Baron TH, Davila RE et al (2005) ASGE guideline: the role of ERCP in diseases of the biliary tract and the pancreas. Gastrointest Endosc 62:1-8

18. Winick AB, Waybill PN, Venbrux AC (2001) Complications of percutaneous transhepatic biliary interventions. Tech Vasc Interv Radiol 4:200-206

19. Clouse ME, Evans D, Costello P, Alday M, Edwards SA, McDermott WV Jr (1983) Percutaneous transhepatic biliary drainage. Complications due to multiple duct obstructions. Ann Surg 198:25-29

20. Davids PH, Tanka AK, Rauws EA, van Gulik TM, van Leeuwen DJ, de Wit LT, Verbeek PC, Huibregtse K, van der Heyde MN, Tytgat GN (1993) Benign biliary strictures. Surgery or endoscopy? Ann Surg 217:237-243
21. Judah JR, Draganov PV (2007) Endoscopic therapy of benign biliary strictures. World J Gastroenterol 13:3531-3539

22. Raute M, Podlech P, Jaschke W, Manegold BC, Trede M, Chir B (1993) Management of bile duct injuries and strictures following cholecystectomy. World J Surg 17:553-562

23. Tocchi A, Mazzoni G, Liotta G, Costa G, Lepre L, Miccini M, De ME, Lamazza MA, Fiori E (2000) Management of benign biliary strictures: biliary enteric anastomosis vs endoscopic stenting. Arch Surg 135:153-157

24. Chapman WC, Halevy A, Blumgart LH, Benjamin IS (1995) Postcholecystectomy bile duct strictures. Management and outcome in 130 patients. Arch Surg 130:597-602

25. Pellegrini CA, Thomas MJ, Way LW (1984) Recurrent biliary stricture. Patterns of recurrence and outcome of surgical therapy. Am J Surg 147:175-180

26. Pitt HA, Miyamoto T, Parapatis SK, Tompkins RK, Longmire WP Jr (1982) Factors influencing outcome in patients with postoperative biliary strictures. Am J Surg 144:14-21

27. Walsh RM, Henderson JM, Vogt DP, Brown N (2007) Long-term outcome of biliary reconstruction for bile duct injuries from laparoscopic cholecystectomies. Surgery 142:450-456

28. de Reuver PR, Raws EA, Vermeulen M, Dijkgraaf MG, Gouma DJ, Bruno MJ (2007) Endoscopic treatment of post-surgical bile duct injuries: long term outcome and predictors of success. Gut 56:1599-1605

29. Schumacher B, Othman T, Jansen M, Preiss C, Neuhaus H (2001) Long-term follow-up of percutaneous transhepatic therapy (PTT) in patients with definite benign anastomotic strictures after hepaticojejunostomy. Endoscopy 33:409-415

30. Ferrucci JT Jr, Mueller PR, Harbin WP (1980) Percutaneous transhepatic biliary drainage: technique, results, and applications. Radiology 135:1-13

31. van der Velden JJ, Berger MY, Bonjer HJ, Brakel K, Lameris JS (2000) Percutaneous treatment of bile duct stones in patients treated unsuccessfully with endoscopic retrograde procedures. Gastrointest Endosc 51:418-422

32. Frattaroli FM, Reggio D, Guadalaxara A, Illomei G, Pappalardo G (1996) Benign biliary strictures: a review of 21 years of experience. J Am Coll Surg 183:506-513

33. Lillemoe KD (1997) Benign post-operative bile duct strictures. Baillieres Clin Gastroenterol 11:749-779

34. Sicklick JK, Camp MS, Lillemoe KD et al (2005) Surgical management of bile duct injuries sustained during laparoscopic cholecystectomy: perioperative results in 200 patients. Ann Surg 241:786-792

35. Goldman LD, Steer ML, Silen W (1983) Recurrent cholangitis after biliary surgery. Am J Surg 145:450-454

36. Matthews JB, Baer HU, Schweizer WP, Gertsch P, Carrel T, Blumgart LH (1993) Recurrent cholangitis with and without anastomotic stricture after biliary-enteric bypass. Arch Surg 128:269-272

37. Misra S, Melton GB, Geschwind JF, Venbrux AC, Cameron JL, Lillemoe KD (2004) Percutaneous management of bile duct strictures and injuries associated with laparoscopic cholecystectomy: a decade of experience. J Am Coll Surg 198:218-226

38. Mueller PR, vanSonnenberg E, Ferrucci JT Jr, Weyman PJ, Butch RJ, Malt RA, Burhenne HJ (1986) Biliary stricture dilatation: multicenter review of clinical management in 73 patients. Radiology 160:17-22 